\title{
Radionuclide determined pulmonary blood volume in ischaemic heart disease
}

\author{
WJ HANNAN, J VOJACEK, HM CONNELL, NG DEWHURST, AL MUIR \\ From the Department of Medical Physics and Medical Engineering, and Department of Medicine, \\ University of Edinburgh, Royal Infirmary, Edinburgh
}

ABSTRACT Most measurements of pulmonary blood volume have been based on the StewartHamilton dye dilution principle and have required direct catheterisation of the cardiac chambers. Alternatively a precordial counter may be used to detect the composite right and left heart curves after an intravenous injection of radionuclide. We investigated the use of a gamma camera/computer system to determine the radionuclide dilution curves from individual cardiac chambers. Pulmonary transit time and pulmonary blood volume were measured in nine normal subjects, eight patients with angina pectoris but without heart failure, and 13 patients with ischaemic heart disease and left ventricular failure. Patients with heart failure had significantly greater $(p<0.001)$ pulmonary blood volumes and pulmonary transit times than normal subjects or patients without heart failure. Reproducibility measurements of pulmonary blood volume, determined in 12 subjects, gave a coefficient of variation of $2 \cdot 6 \%$. The effect of posture on pulmonary blood volume was determined in six subjects lying supine and tilted at a $45^{\circ}$ angle. A reduction in pulmonary blood volume in the tilted position was observed in each subject $(\mathrm{p}<0.005)$. This simple non-invasive measurement should allow more detailed assessment of physiological or pharmacological changes of the pulmonary vascular bed.

Our knowledge of the haemodynamics of the pulmonary vascular bed is based on the measurement of three main variables: the pulmonary blood pressure, pulmonary blood flow, and pulmonary blood volume. Of these three, pulmonary blood volume has been the most difficult to assess and therefore has found little clinical favour, yet changes in pulmonary blood volume are of importance in understanding a wide variety of clinical problems. In animal studies pulmonary blood volume is increased when pulmonary venous pressure is increased. ${ }^{1} \mathrm{~A}$ similar relation has been documented in man..$^{2-5}$ Thus an increase in pulmonary blood volume should serve as an early indicator of left ventricular failure. Moreover drugs used in the treatment of acute pulmonary oedema such as frusemide probably cause immediate relief of symptoms by a reduction in pulmonary blood volume. ${ }^{6}$ Changes in pulmonary blood volume should be of diagnostic and therapeutic importance

Address for reprint requests: Dr WJ Hannan, Department of Medical Physics and Medical Engineering, Royal Infirmary, Edinburgh EH3 9YW. but the technical difficulties associated with its measurement have limited its use. Most measurements of this volume have been based on the StewartHamilton dye dilution technique. Early measurements based on an injection of indicator into the great veins with sampling in arteries yielded a "central blood volume", which included the volume of blood in all the cardiac chambers. More precise anatomical definition of the pulmonary blood volume was obtained, first by injections made into the pulmonary artery, and secondly by either a second injection or dye sampling from the left atrium. However, streaming effects caused by injection into the pulmonary artery or left atrium, or delays and damping effects caused by left atrial sampling, produce potential errors. Moreover, these methods require direct catheterisation of the various cardiac chambers. An alternative non-invasive method was that of Guintini et al ${ }^{7}$ who used a precordial counter to detect the passage of a bolus of radioisotope through the heart. A composite right and left heart curve was obtained and by assuming a "turn-over" time for the right ventricle, they were able to obtain separate curves from the 
right and left sides of the heart, and from these they were able to derive a mean transit time for the pulmonary circulation.

In contrast to the use of a single scintillation probe modern gamma camera/computer systems allow indicator dilution curves to be determined for individual cardiac chambers and provide a new opportunity for the non-invasive determination of pulmonary blood volume. In this study we have investigated the reproducibility of the method and alterations in pulmonary blood volume caused by posture and have compared pulmonary blood volume in normal subjects and in patients with ischaemic heart disease with and without left ventricular failure.

\section{Methods}

We studied 30 patients who had been referred for routine radionuclide ventriculography; all were in sinus rhythm. Nine had atypical chest pain and were shown to have normal ventricular function at rest and exercise. They were deemed to have normal cardiac function. Eight patients had angina pectoris, but had no clinical or radiological evidence of heart failure. Thirteen patients had ischaemic heart disease with clinical and radiological evidence of left ventricular failure; all of these patients were receiving diuretic therapy at the time of the study. The patients were informed of the nature and purpose of the study and consented to take part.

Patients were studied in the supine position beneath a Nuclear Enterprises Mk 5 HR gamma camera containing a high sensitivity parallel hole collimator. The camera was positioned in the $30^{\circ}$ left anterior oblique projection with a $10^{\circ}$ caudal tilt to give the optimum separation of the right and left chambers of the heart. Fifteen $\mathrm{mCi}(555 \mathrm{MBq})$ of technetium-99m electrolytically labelled to human serum albumin ${ }^{8}$ was given by rapid intravenous injection followed by a saline flush. The counts detected during the initial passage through the cardiac chambers, and also the subsequent four minute equilibration period, were stored in list mode on a PDP 11/34 computer (Digital Equipment Corporation). One millimetre of blood was withdrawn from the opposite arm to the injection site. By comparing the activity in this blood with the activity injected, the patient's blood volume was calculated. As only plasma was labelled the true blood volume was derived by correcting the venous haematocrit to the whole body haematocrit. ${ }^{9}$

After the equilibration period the counts from the precordium were stored in $\mathbf{4 0} \mathrm{ms}$ frames in computer memory. The accumulation was triggered by the $\mathrm{R}$-wave of the patient's electrocardiogram, each frame being updated by successive cardiac cycles until 500 heart beats had been accumulated. Our method of calculating left ventricular ejection fraction (EF) has been described eleswhere. ${ }^{10}$ Essentially this consisted of displaying the sequence of images in "movie" format on a television display. The left ventricular outline at end diastole was identified and from this region a background corrected volume-time curve was generated throughout the cardiac cycle. Ejection fraction was automatically calculated from the detected counts at end diastole and end systole.

Cardiac index was derived from the radionuclide dilution from the left ventricle (fig 1) after correcting for dead-time losses in the gamma camera. The area (A), corresponding to the initial passage of radionuclide, was determined using a gamma variate fitting technique ${ }^{11}$ to remove the recirculation portion. This fit was performed between approximately $20 \%$ of the peak height on the upslope and $50 \%$ on the downslope. The average correlation coefficient between the original and the fitted data between these limits was $0.985 \pm 0.004$ (SD). The equilibrium height $(\mathrm{H})$ was the average height between three and four minutes post injection. Cardiac index (CI) was then derived from the relation:

$$
\mathrm{CI}=(\text { blood volume. } \mathrm{H}) /(\mathrm{A} . \mathrm{BSA})
$$

where BSA was the patient's body surface area.

The stroke index (SI) of the left ventricle was obtained by dividing the cardiac index by the heart rate, where the heart rate was derived from the R-R interval histogram stored in the computer during the ECG-gated phase of the study.

The end-diastolic volume index (EDVI) of the left ventricle was also obtained by dividing the stroke index by the left ventricular ejection fraction.

For vascular systems in series the mean transit time through the system is the sum of the mean transit times through the members of the series. ${ }^{12}$ Measurement of indicator dilution curves from right and left ventricles would give a "pulmonary" mean transit time which would include contributions of all vascular sections from the right ventricle to the aortic valve. To exclude the right ventricle, we obtained an indicator dilution curve from the main pulmonary artery. In a number of patients we were also able to obtain satisfactory curves from the left atrium when the camera was positioned with a $30^{\circ}$ caudal tilt, but as the left atrium could not be easily identified in all patients, we therefore used indicator dilution curves from the left ventricle. From these two dilution curves (fig 1) the mean central transit time (MCT) was derived from the difference in the mean transit times (MTT), where the mean transit time was calculated as: 


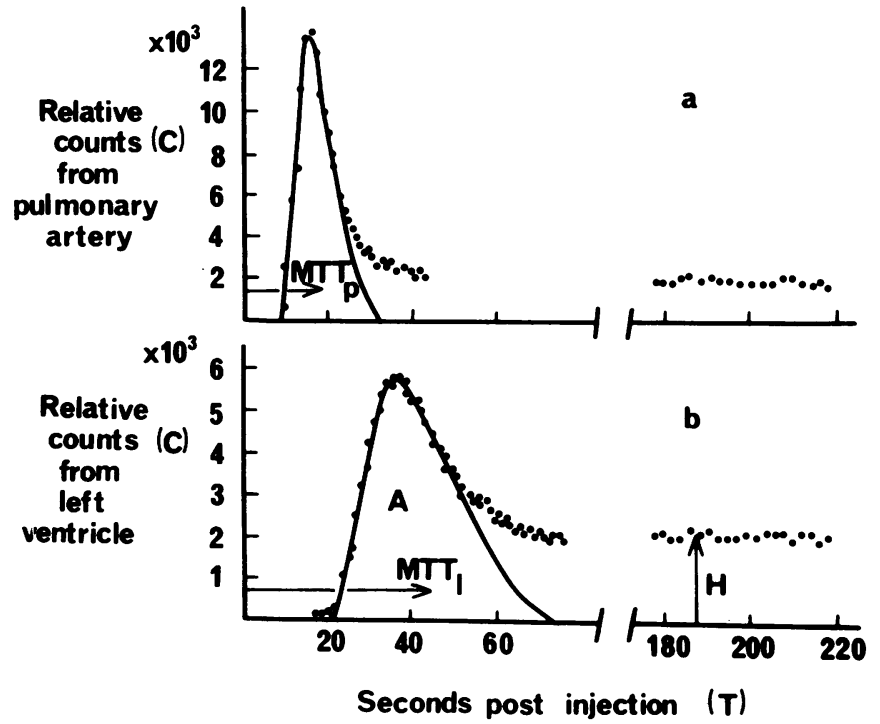

Fig 1 Radionuclide dilution curves from (a) the main pulmonary artery and (b) the left ventricle. The solid lines represent the gamma variate fits to the initial passage of the radionuclide bolus. The mean transit times through the two chambers are $M T T_{p}$ and $M T T_{l}$ respectively. The area corresponding to the initial passage through the left ventricle is given by $A$ and the average height of the curve at equilibrium is $H$.
$\mathbf{M T T}=\sum\left(\mathbf{C}_{\mathbf{i}} \cdot \mathbf{T}_{\mathbf{i}}\right) / \sum \mathbf{C}_{\mathbf{i}}$

where $C_{i}$ is the detected count at time $T_{1}$.

To account for the contribution of the left ventricle, the mean transit time from this chamber (MVT) was derived from the relation $M V T=R R / \log _{e}(1 /(1-E F))$ (Appendix). The use of this relationship is valid because over a wide range of cardiac output and left ventricular ejection fraction, the clearance of radionuclide from the left ventricle is represented by a single exponential, indicating adequate mixing. Thus the mean pulmonary transit time (MPT) is MPT = MCT - MVT. This mean pulmonary transit time will also contain a component representing the left atrium.

The pulmonary blood volume index (PVBI) was obtained by multiplying the cardiac index by the mean pulmonary transit time. Statistical analysis was carried out using the non-paired Student's $t$ test. Values of $\mathrm{p}$ greater than $\mathbf{0 . 0 5}$ were not considered to be significant.

\section{Results}

We have previously reported ${ }^{13}$ the reproducibility of ejection fraction, cardiac index, and end-diastolic volume measurements, showing a coefficient of variation of less than $4 \%$. The mean values of ejection fraction for the control, heart disease, and heart failure groups were $0.56 \pm 0.04$ (SD), $0.47 \pm$ 0.04 , and $0.22 \pm 0.10$ respectively (fig 2 ). Cardiac index was only significantly reduced $(p<0.001)$ in patients with heart failure, where there was a reduction of $33 \%$ in the mean values. The mean value of stroke index was reduced by $43 \%$ in patients with heart failure $(\mathrm{p}<0.001)$. The greater reduction in stroke index reflects the general increase in heart rate in those with heart failure. The mean enddiastolic volume index was $95 \pm 17$ (SD) $\mathrm{ml}^{-\mathrm{m}^{-2}}$ in the control group and $164 \pm 72 \mathrm{ml} . \mathrm{m}^{-2}$ for the patients in heart failure $(\mathrm{p}<0.01)$.

The mean pulmonary transit times are shown in fig 3. The average value for the control group was $4.9 \pm 0.8$ (SD) seconds (range 3.8-6.6) and for the patients in heart failure was $10 \cdot 3 \pm 4 \cdot 1$ seconds (range 5.2-20.5) $(\mathrm{p}<0.001)$. No significant difference was found between the control group and the patients with heart disease without failure. The increase in pulmonary transit time in heart failure was even more marked when normalised by the mean $\mathbf{R}-\mathbf{R}$ interval. The average value of this ratio was $6.5 \pm 1.2$ (SD) (range 4.4-8.0) for the control group and 16.0 \pm 6.5 (range 8.7-28.5) for the heart failure patients $(p<0.001)$. This again reflects the partial compensating effect of an increase in heart rate during failure. The pulmonary blood volume index was $335 \pm 70$ (SD) $\mathrm{ml}^{-2}$ for the control group and $455 \pm 65 \mathrm{ml} \cdot \mathrm{m}^{-2}(\mathrm{p}<0.001)$ for the patients in heart failure. No significant increase was found in the patients with heart disease without failure.

The ratio of pulmonary to total blood volume was also increased in patients with heart failure (controls $0.13 \pm 0.03$ (SD); IHD $0.13 \pm 0.02 ;$ IHD + failure $0.17 \pm 0.03(p<0.005))$.

In order to assess the reproducibility of the measurement of pulmonary blood volume, repeat measurements were made on 12 of the patients (three controls, six IHD, and three IHD and failure). 


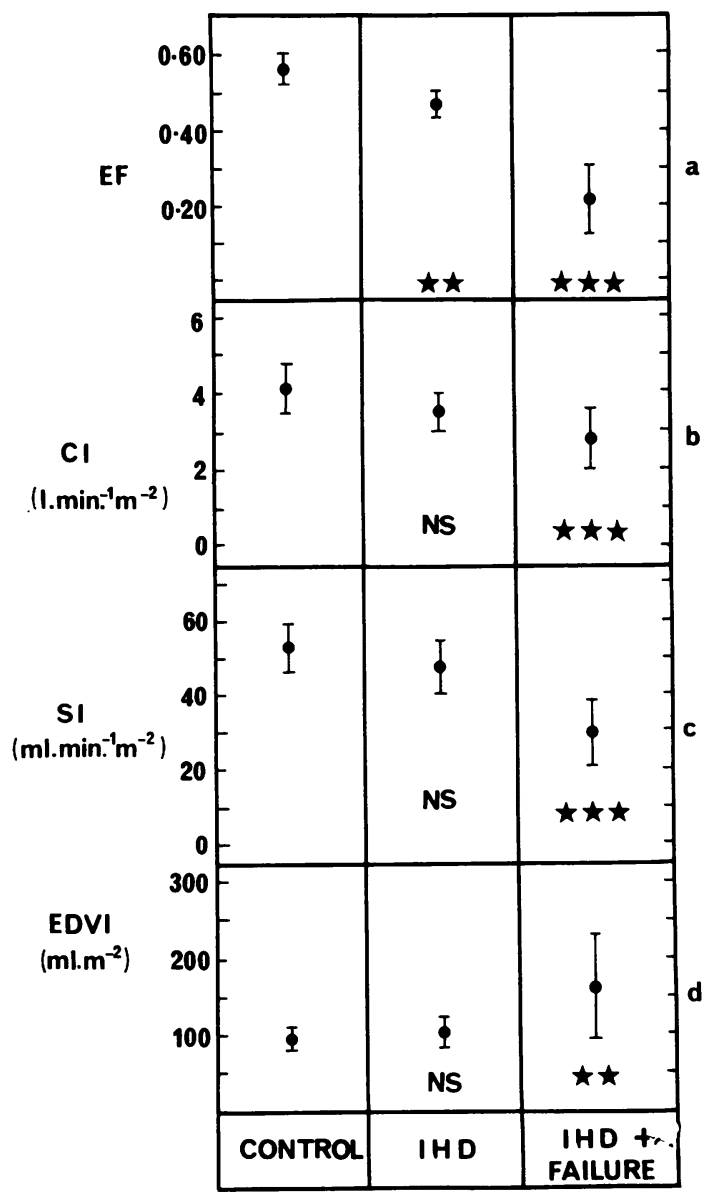

Fig 2 The values of (a) left ventricular ejection fraction, (b) cardiac index, (c) stroke index, and (d) end-diastolic volume index for the control group and the patients with ischaemic heart disease with and without heart failure. Mean values and standard deviations are shown. All data were compared with the control group using Student's $t$ test; NS not significant; ${ }^{* *} p<0.01$; *** $p<0.001$.

An initial bolus injection of $5 \mathrm{mCi}$ of technetium$99 \mathrm{~m}$ labelled albumin was followed five minutes later by a $10 \mathrm{mCi}$ bolus injection. When analysing the indicator dilution curves for the second injection, the background counts were subtracted before performing the gamma variate fit. The average difference in the two measurements of pulmonary blood volume was $5.3 \%$ (coefficient of variation $2.6 \%$ ).

To assess the effect of posture on blood volume, the pulmonary blood volume index was measured in six patients lying supine and also at a $45^{\circ}$ head up angle on a tilt table (fig 4). Five of these patients

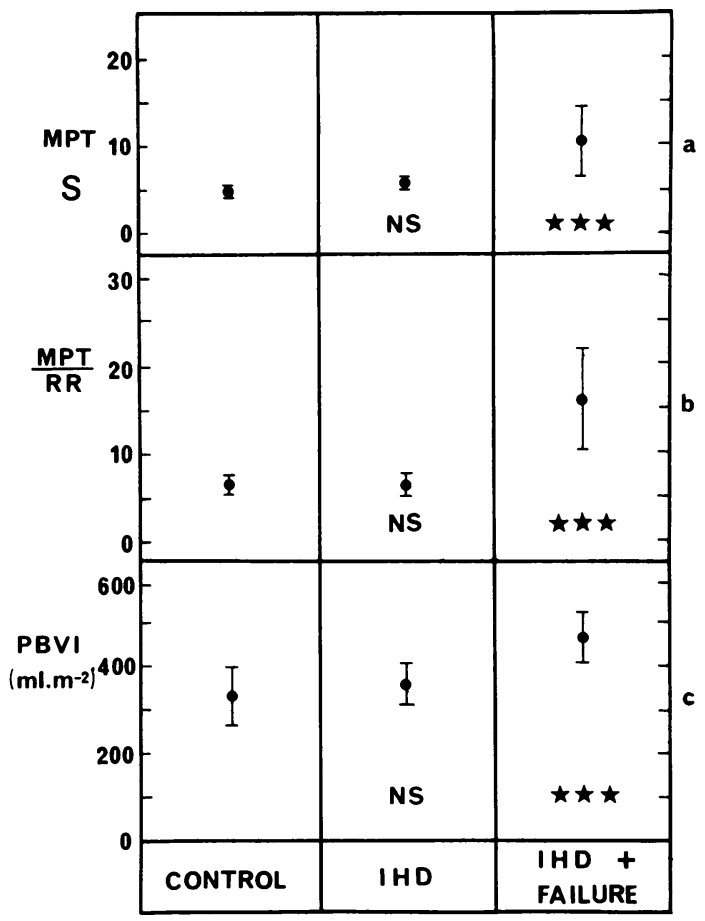

Fig 3 (a) Mean pulmonary transit time, (b) the ratio of mean pulmonary transit time to $R R$ interval, and (c) pulmonary blood volume index for the control group and for the patients with ischaemic heart disease with and without heart failure. Mean values and standard deviations are shown. Data were compared with the control group using Student's t test; NS not significant; ${ }^{* * *} p<0.001$.

had radiological evidence of heart failure. The mean pulmonary blood volume index for this group was $435 \pm 55$ (SE) ml.m $\mathrm{m}^{-2}$ in the supine position and $326 \pm 47$ (SE) $\mathrm{ml}^{-2} \mathrm{~m}^{-2}$ in the tilted position ( $\mathrm{p}<$ 0.005 ). The mean reduction in pulmonary blood volume was $20 \cdot 3 \% \pm 2 \cdot 6 \%$ (SE).

\section{Discussion}

Early attempts to measure pulmonary blood volume by radionuclides assumed no substantial recirculation of indicator into the right side of the heart while the left heart indicator curve was being recorded. Guintini and colleagues? introduced a technique that avoided this potential error. They assumed the volume of the two ventricles was the same and that there was no intervening pulmonary circulation. In these circumstances the peak concentration of indicator in the left ventricle after instantaneous injection into the right ventricle would occur at a time when the volume of blood which had 


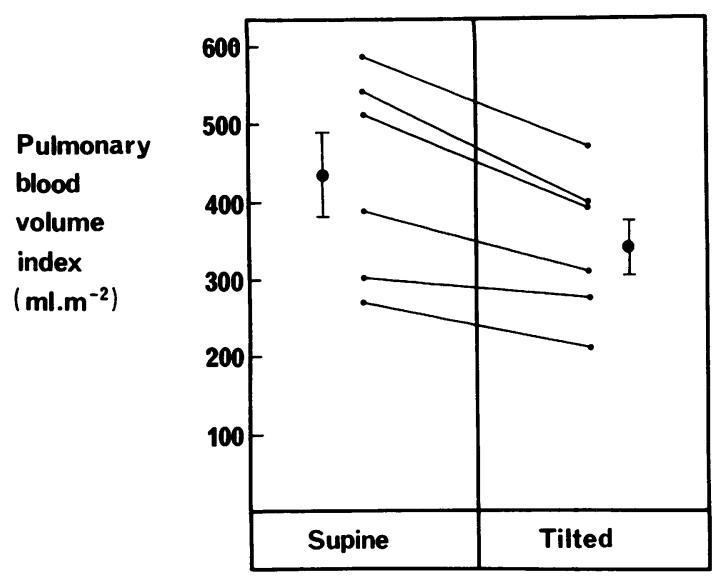

Fig 4 Pulmonary blood volume index in six patients lying supine and sitting tilted at $a 45^{\circ}$ angle. $A$ reduction was observed in the tilted posture in each subject. Mean values and standard errors are also shown. Results compared by Student's paired t test were significantly different $(p<0.005)$.

flowed through the right ventricle was equal to the volume of the ventricle. This was the "turn-over time" of the ventricle and at that time the concentration of indicator in the right ventricle was $37 \%$ of its theoretical initial value. With a pulmonary circulation between the two ventricles, the peak of the left ventricular indicator concentration becomes separated from the right ventricular "turn-over time" and the degree of separation is a measure of the mean transit time in the pulmonary circulation. Their method also avoids analysis of the downslope of the left ventricular indicator curve which may be difficult when dealing with a "composite" curve produced by a single scintillation probe.

Modern gamma camera systems avoid the problems of "composite" curves for they allow each chamber to be identified and individual indicator dilution curves to be inscribed. Any "contamination" from the other chambers, or from background activity can be overcome by using a gamma variate fitting procedure. Thus the pulmonary blood volume can be derived, based on a straightforward application of the Stewart-Hamilton dye dilution method. However, based on an analysis of the two ventricular curves, the central volume measured will include the volume of the right and left ventricle and the left atrium. By increasing the caudal angulation of the gamma camera head, in a number of patients a left atrial curve can be inscribed. However, the left atrium is not seen sufficiently often in all patients to rely on sampling from this chamber. Right ventricular volume can be excluded by sampling from the
Table Pulmonary blood volume index $\left(\mathrm{ml} . \mathrm{m}^{-2}\right)$

\begin{tabular}{|c|c|c|c|c|}
\hline Authors & Subjects & Number & Range & Mean \\
\hline Dock et $a l^{2}$ & $\begin{array}{l}\text { Controls } \\
\text { Aortic and/or } \\
\text { mitral valve } \\
\text { disease }\end{array}$ & $\begin{array}{r}4 \\
41\end{array}$ & $\begin{array}{l}219-269 \\
172-634\end{array}$ & $\begin{array}{l}246 \\
322\end{array}$ \\
\hline Milnor et $a l^{3}$ & $\begin{array}{l}\text { Aortic and/or } \\
\text { mitral valve } \\
\text { disease }\end{array}$ & 19 & $126-598$ & 365 \\
\hline Oakley et $a l^{4}$ & $\begin{array}{l}\text { Aortic and/or } \\
\text { mitral valve } \\
\text { disease }\end{array}$ & 44 & $122-455$ & 283 \\
\hline Lewis et al ${ }^{5}$ & $\begin{array}{l}\text { Controls } \\
\text { Aortic and/or } \\
\text { mitral valve } \\
\text { disease + CCF }\end{array}$ & $\begin{array}{l}13 \\
11\end{array}$ & $\begin{array}{l}201-357 \\
266-446\end{array}$ & $\begin{array}{l}301 \\
373\end{array}$ \\
\hline \multirow[t]{2}{*}{ Present series } & $\begin{array}{l}\text { Controls } \\
\text { Ischaemic heart } \\
\text { disease (IHD) }\end{array}$ & $\begin{array}{l}9 \\
8\end{array}$ & $\begin{array}{l}225-426 \\
309-460\end{array}$ & $\begin{array}{l}335 \\
359\end{array}$ \\
\hline & IHD + CCF & 8 & $328-588$ & 455 \\
\hline
\end{tabular}

main pulmonary artery. As the clearance from the left ventricle is essentially represented by a single exponential, a mean transit time through the left ventricle can be derived (Appendix), and this ventricular transit time is then subtracted from the central transit time to yield a pulmonary transit time. When multiplied by the cardiac output this now measures the volume of the circulation from the pulmonary valve to the mitral valve.

This method yields values for pulmonary blood volume that replicate well, are responsive to changes in posture, and are in broad agreement with previous published values (table). The results of Dock, ${ }^{2}$ Milnor, ${ }^{3}$ Oakley $^{4}$ and their colleagues suggest slightly lower values than those obtained by ourselves and by Lewis and colleagues. ${ }^{16}$ The first three groups used direct left atrial catheterisation so that left atrial volume would not be included in the calculated pulmonary blood volume. Lewis et al, ${ }^{5}$ using the radiocardiographic method, developed by Guintini and colleagues, ${ }^{7}$ sampled the isotope dilution by a scintillation probe and correlated the results with pulmonary blood volume measured by injection of indocyanine green into the pulmonary artery and into the left atrium. They found good correlation between the two methods over a wide range of values. The apparent tendency of the isotope method to exceed the indocyanine green method did not achieve statistical significance. The principal technical problem with the isotope indicator dilution method is to achieve a satisfactory bolus injection. The most satisfactory system that we have found was to inject the volume of the indicator $(1 \mathrm{ml})$ into the dead space of the intravenous catheter. When the bolus was to be injected into the patient, the system was flushed rapidly with $20 \mathrm{ml}$ of normal saline.

In this study we have shown that patients with 
congestive cardiac failure, complicating ischaemic heart disease, have significantly lower ejection fractions, cardiac outputs, and stroke volumes than either control subjects or patients with ischaemic heart disease without heart failure. Similarly, they have higher end-diastolic volumes. Analysis of the pulmonary circulation shows they also have significantly higher pulmonary blood volumes and mean pulmonary transit times. As the precise value of mean pulmonary transit time will depend on the heart rate at the time of measurement we have constructed a new index of mean pulmonary transit time divided by the $R-R$ interval. This index is significantly increased in the patients with congestive cardiac failure and indeed provides better discrimination between those with and without failure than the pulmonary blood volume alone.

Our investigations show that the modern gamma camera/computer system allows the determination of pulmonary blood volume in a simple and noninvasive fashion. Knowledge of the haemodynamics of the pulmonary vascular bed in health and disease and in response to drug therapy can now be extended.

\section{References}

${ }^{1}$ Sarnoff SJ, Berglund E, Sarnoff LC. Neuro-hemodynamics of pulmonary edema. III Estimated changes in pulmonary blood volume accompanying systemic vasoconstriction and vascdilation. J Appl Physiol 1952/53;5: 367-74.

${ }^{2}$ Dock DS, Kraus WL, McGuire LB, Hyland JW, Haynes FW, Dexter $\mathrm{L}$. The pulmonary blood volume in man. J Clin Invest 1961;40:317-28.

${ }^{3}$ Milnor WR, Jose AD, McGaff CJ. Pulmonary vascular volume, resistance and compliance in man. Circulation 1960;22:130-7.

4 Oakley C, Glick G, Luria MN, Schreiner BF, Yu PN. Some regulatory mechanisms of the human pulmonary vascular bed. Circulation 1962;26:917-30.

${ }^{5}$ Lewis ML, Gnoj J, Fisher VJ, Christianson LC. Determinants of pulmonary blood volume. J Clin Invest 1970; 49:170-82.

- Dikshit K, Vyden JK, Forrester JS, Chatterjee K, Prakash R, Swan HJC. Renal and extrarenal hemodynamic effects of furosemide in congestive heart failure after myocardial infarction. $N$ Engl J Med 1973;288:1087-90.

7 Guintini C, Lewis ML, Sales Luis A, Harvey RM. A study of the pulmonary blood volume in man by gravitational radiocardiography. J Clin Invest 1963;42:1589-605.

${ }^{8}$ Millar AM, Hannan WJ, Sapru RP, Muir AL. An evaluation of six kits of technetium $99 \mathrm{~m}$ human serum albumin injection for cardiac blood pool imaging. Eur $J$ Nucl Med 1979;4:91-4.

${ }^{9}$ International Committee for Standardisation in Haematology (ICSH) 1973 Report: Panel on Diagnostic
Applications of Radioisotopes in Haematology: Standard techniques for the measurement of red-cell and plasma volume. Br J Haematol 1973;25:801-14.

10 Muir AL, Hannan WJ, Sapru RP, Boardman AK, Wraith PK, Brash HM. The effects of isoprenaline, atropine and dobutamine on ventricular volume curves obtained by radionuclide ventriculography. Clin Sci 1980;58:357-64.

${ }^{11}$ Starmer CF, Clark DO. Computer computations of cardiac output using the gamma function. J Appl Physiol 1970; 28:219-20.

12 Zierler KL. Circulation times and the theory of indicator dilution methods for determining blood flow and volume. In: Hamilton WF, ed. Handbook of Physiology. Section 2, Circulation volume 1. Washington: American Physiological Society, 1962.

${ }^{13}$ Hannan WJ, Vojacek J, Dewhurst NJ, Muir AL. The sequential measurement of ventricular volumes and cardiac output by radionuclices. Clin Phys Physiol Meas $1980 ; 1: 125-34$.

\section{Appendix}

Since the radioactive bolus is well mixed by the time it reaches the left ventricle, the observed single exponential clearance from this chamber may be expressed as:

$\mathrm{C}_{\mathrm{t}}=\mathrm{C}_{\mathrm{o}} \cdot \exp (-\mathrm{Bt})$

where $C_{t}$ is the count rate at time $t, C_{o}$ is the initial count rate and $B$ is a constant.

When the time is equal to the patient's R-R interval $(t=R R)$, the count rate $\left(C_{R R}\right)$ is related to the initial count rate by the relationship:

$\mathrm{C}_{\mathrm{RR}}=\mathrm{C}_{\mathrm{o}}$. $(1-\mathrm{EF})$

where $E F$ is the left ventricular ejection fraction.

Equating (1) and (2) gives:

$\exp (-\mathrm{B} . \mathrm{RR})=1-\mathrm{EF}$

from which the constant, $\mathrm{B}$, may be derived as:

$\mathrm{B}=\frac{\log _{\mathrm{e}}\left(\frac{1}{1-\mathrm{EF}}\right)}{\mathrm{RR}}$

The mean transit time through the left ventricle (MVT) is given by

$$
\begin{aligned}
\text { MVT } & =\frac{\int_{0}^{\infty} t \cdot \exp (-B t) \cdot d_{t}}{\int_{0}^{\infty} \exp (-B t) \cdot d t} \\
& =\frac{1}{\bar{B}}
\end{aligned}
$$

Therefore the mean transit time through the left ventricle may be calculated from the patient's ejection fraction and $R-R$ interval using the relationship.

$$
\mathrm{MVT}=\frac{\mathrm{RR}}{\log _{\mathrm{e}}\left(\frac{1}{1-\mathrm{EF}}\right)}
$$

